\title{
A Conversation with David Bartel
}

\author{
INTERVIEWER: RICHARD SEVER \\ Assistant Director, Cold Spring Harbor Laboratory Press
}

\begin{abstract}
David Bartel is a Professor of Biology, a Member of the Whitehead Institute, and an Investigator at the Howard Hughes Medical Institute at the Massachusetts Institute of Technology.
\end{abstract}

Richard Sever: You spoke yesterday about microRNAs, the small RNAs that regulate the activity of genes posttranscriptionally. You made the point that the effects of knocking down these microRNAs could be really debilitating. That was kind of a shock to me because people are always saying that it's a fine-tuning of gene expression. Can you say a little bit more about that?

Dr. Bartel: I like the term "tuning" rather than "fine-tuning" because it actually is more of a tuning. It turns out that these microRNAs do have very striking phenotypes when you knock them out, but even before we knew the knockout phenotypes, we knew that they recognized many targets. We know that there are 90 families of microRNAs highly conserved from humans to fish. Each of those 90 have on average about 400 preferentially conserved targets. That adds up to more than half of the human genes that are conserved targets of microRNAs. On average, they're targeted by four or five different microRNAs. They [the microRNAs] have these very widespread effects.

It is true that for each microRNA-target interaction, that [regulation] can be a rather subtle - maybe 20\% - downregulation, sometimes $30 \%$, sometimes more. But because they have so many targets, when you knock out the microRNA in mice- - which is what many labs have been doing; they've knocked out one or several members of the same family of microRNAs - and when they look at the phenotypes, for these 90 conserved families nearly every one of them where knockouts have been reported on, they certainly do see a phenotype. They've looked at over half of them and seen phenotypes. We already know that 15 of these microRNA families, when you knock them out, you have embryonic lethality or perinatal lethality, so that's pretty severe. And there are others that also have [other] very severe phenotypes like blindness, deafness, infertility, seizures, epilepsy, cancer, etc. There's a huge range of phenotypes - and many of them very severe - from the microRNAs. So, we know that they're playing very important roles.

Richard Sever: Are you saying that the severity of the phenotype is not because of the quantitative effect on any given gene, but just because you're hitting a whole bunch of them?

Dr. Bartel: I think that's the easiest way to think about it. In some cases, people have found single individual targets where that $50 \%$ down-regulation has a dramatic effect. But even there, they have hundreds of other targets that are conserved more than they would expect by chance. Certainly, over the course of evolution we know that biology cares about many more than single targets, and, again, each of them is regulated by a relatively small amount of tuning. So, that's our current view of what's occurring.

Richard Sever: For those of us stuck in the '90s, how does that compare with the way we think of transcription factors? Do you think that we shouldn't be singling these out as different in the way they work?

Dr. Bartel: Depending upon the transcription factor, you might also see these minor effects on many targets; it may not be that much different. There are some transcription factors that will have a 40- or 50-fold effect on the transcription of a certain mRNA, but I think, more generally, transcription factors might also have widespread effectson the level of microRNAs - and may not be a lot different for a lot of those interactions.

Richard Sever: The way the microRNAs act is by exerting their effects on messenger RNA [mRNA]. There's two possibilities there: stopping its translation, and degrading it. You've made the point that actually it's much more of one than the other.

Dr. Bartel: What we see is that-with one exceptionevery place where we've looked, over two-thirds of the repression could be explained by the microRNA recruiting factors that deadenylate the RNA and then cause the RNA to get destabilized. Often, over $90 \%$ can be explained by this degradation mechanism, leaving somewhere between $10 \%$ (sometimes less) up to a third with this additional mode of repression that's through translational repression -inhibiting, presumably, translation initiation. So, in general, the majority of the effects that we see are through this mRNA destabilization.

(C) 2019 Bartel. This article is distributed under the terms of the Creative Commons Attribution License, which permits unrestricted reuse and redistribution provided that the original author and source are credited. 
The exception, which is really interesting, is that in early zebrafish [embryos], you completely miss what the microRNAs are doing by looking at the changes in mRNA levels. Whereas everywhere else-it's kind of nice-you can perturb the microRNA and be able to know what the targets and the effects of the microRNAs [are] just by looking at changes in mRNA, which is much easier to do than looking at changes in protein or ribosome-protected fragments. But, in the zebrafish [embryos], that would not work at all. That was shown by Antonio Giraldez's lab - that in the early zebrafish embryo, the effects of the microRNAs could only be seen when you look at the changes in ribosome-protected fragments.

Richard Sever: That's this early phase of development in zebrafish. Is it early phases of development in other organisms or is it something unique to a particular lineage?

Dr. Bartel: It's a good question. I think that the same will probably also hold in frogs and in flies, but I'm not sure that people have done those experiments. We do understand what's going on in zebrafish, and we think-based on what we see in these other organisms - that it'll also hold there.

The effects of the microRNAs is that they recruit a protein called TNRC6 [trinucleotide-repeat-containing $6]$ that in turn recruits the deadenylation complexes, the Pan2-Pan3 or Ccr4-Not complexes, and that causes the poly(A) tail to get shorter. Once the tail gets to be a certain length, you get decapping and decay of the mRNA.

What we see in early zebrafish is that the microRNAs cause the tail to get shorter, and in that developmental context - in that regulatory regime - what we find is that mRNAs with short tails are translated much less efficiently than mRNAs with long tails. There's this very strong coupling in the early zebrafish, before gastrulation, where short-tailed mRNAs are translated much less efficiently than long-tailed [mRNAs]. What's interesting is that that goes away at $6 \mathrm{~h}$ postfertilization, which is the [time of] gastrulation of the fish. At that point, the microRNA also causes the tail to get shorter, but in that context, a short tail leads to [mRNA] degradation.

Richard Sever: Sticking with the pregastrulation scenarios, is there an a priori reason for that? Going back to this kind of tunability, if you're stopping a translation rather than degrading the RNA, does that give you more ability to tune? Is it reversible?

Dr. Bartel: I think you're onto it there. I'll just add that we see this same sort of transition in translational control in frogs and in flies, and this coupling between the length of the tail and the efficiency of translation-which is very strong in the early embryo of frogs, flies, fish - is also very strong in oocytes, and then goes away around gastrulation. The reason that we think that there is that coupling between the length of the tail and the efficiency of translation is that this is a time in development - at least up until about $3 \mathrm{~h}$ postfertilization - in which there is no transcription. The mRNA is all maternally inherited, and yet the embryo cells still need a way to regulate genes. They can't do it by transcription, and so the way they do it is by changing the tail length. They have this phenomenon called cytoplasmic polyadenylation, which will extend the length of the tail, and that will cause a massive increase in translation. They also have other ways of shortening the tail, so they can adjust the amount of protein output [in either direction].

Richard Sever: Do you get an oscillation there?

Dr. Bartel: Yes, [but more generally,] depending on the gene, you can just get different output at different points in early development through this polyadenylation mechanism.

So, then the question is, "Why does it [this coupling between tail length and translation efficiency] go away?" And the reason we think it goes away is that later in development, transcription is already started up, and that's a great way to regulate genes. So, you don't need this taillength control to regulate translational output; instead, what the cells do use is transcription, and they also use mRNA stability. That's what the microRNAs are doing; they're changing the stability of the mRNAs - and that's what we see in all these postembryonic contexts.

When the cell is using mRNA stability to regulate genes, then it's not such a great strategy to only translate the mRNAs with long tails, because those are the mRNAs that just came into the cytoplasm, whereas the RNAs that had been there a long time have shorter tails, and the cell would not want to discriminate against them - it wouldn't want to do this "age discrimination" against the older mRNAs. If it's had those RNAs stable, it wants to use them; it wants to use the RNAs with short tails just as much as it wants to use those with long tails - if it's using mRNA stability as a mechanism for gene regulation. So, the idea is that when the cell switches over to this mechanism of using mRNA stability to regulate genes - which they use a lot; you have these massive differences in mRNA stability - then the cells switch away from controlling translation based on the length of the tail.

Richard Sever: When you were looking at the length of the poly(A) tails, you were discriminating between steady state levels and a better experimental approach to make sure you know what the length is and when. Can you tell us a little bit about that?

Dr. Bartel: Sure. What I described so far was in the early zebrafish embryo, and there it's not really a steady state situation. You have development happening, and you can see these tail-length differences very readily for [the targets of] the microRNAs. But interestingly, if you just look in mouse 3T3 cells - the fibroblast cells of mouse-and you're just growing cells at steady state, and you have a microRNA that you've induced that is there at very high levels, and then you just look at the poly(A)-tail lengths of the mRNA targets of that microRNA, surprisingly, at steady state, you see no difference. The distribution of tail lengths is the same whether or not the mRNA is a target of the microRNA or not. That caused us to realize that we shouldn't really be looking at steady state mea- 
surements. We need to look at pre-steady state. We need to look at what's happening to the newly transcribed mRNAs and beyond and get measurements of the dynamics that you can't get at steady state.

Richard Sever: What's the timeline that you're thinking about them in discriminating the point at which steady state becomes a reasonable measure?

Dr. Bartel: At about $8 \mathrm{~h}$ things have pretty much approached steady state in these cells. There aren't that many mRNAs that have half-lives much longer than that. There's some, but you've pretty much approached steady state by $8 \mathrm{~h}$. So, we'll do a metabolic labeling time course that will take a very early time point, and some intermediate ones, and then $8 \mathrm{~h}$, and then just isolate the RNA that was transcribed over those time intervals and measure the tails. When we do that, we can see there are very clear differences in the microRNA effect; we can see that the microRNAs are clearly shortening the tails [of their targets], which we can see at these intermediate time periods.

Richard Sever: When the tails shorten, is there a threshold at which you're basically done: You're going to get degraded? What's the correlation?

Dr. Bartel: Yes. So we set out to do these experiments to look at this microRNA effect, but we can look at these more general principles of tail-length shortening, deadenylation rates, and then the rate of decay once the mRNA gets to be a short tail length. We can get these measurements, which we knew for a very small set of genes previously [from] people in the '90s, like Ann-Bin Shyu's lab and others in mammalian cells, and Roy Parker's lab in yeast. In mammalian cells, we knew from those early experiments the tail-length dynamics and mRNA-decay dynamics that are associated with tail length for [only] four mRNAs. When we realized that we had the data sets now to be able to look at this for thousands of mRNAs, that was very exciting to us. Now we can use these metabolic-labeling data sets to model - for mRNAs from close to 3000 different genes - we can model the initial tail length when the mRNA goes into the cytoplasm; what is the initial tail length at that early point? And then, how rapidly did the tails get shorter? And then, once they get shorter, how rapidly are they degraded? And we get that information now for close to 3000 mRNAs from 3000 genes.

Richard Sever: Is there a broad spectrum of behavior? Do they all look the same? Does this all happen at $30 \mathrm{nt}$ ?

Dr. Bartel: What we see is that the deadenylation rates for mRNAs from different genes can vary widely - a 1000fold. There are some mRNAs that are deadenylating at 30 nt per minute, and there are others where the tail is shortening at $0.03 \mathrm{nt}$ a minute: 1-2 nt per hour, on average. That's one thing we find.

What's also interesting is that once the tails reach a short length, the rate of decay can also vary a 1000-fold. The short-tailed mRNAs from genes where their mRNAs' tails get shorter more rapidly - once they reach a short tail length, the mRNA decays more rapidly. But, if the tail is deadenylating more slowly, once they've reached a short tail, they get decayed much more slowly. This is very interesting to us. What it does is it prevents the mRNAs that have very rapid deadenylation from accumulating in the cell with very short tails. Otherwise, you could have this big buildup of very short-tailed mRNAs. We just don't see that, and this explains why: It's because for the mRNAs where their tails get shorter more rapidly, they also then decay more rapidly once they reach a short tail length. That allows these huge differences in deadenylation rate - a 1000-fold difference - to impart a similarly large difference in decay rate. And so you could have a really broad spectrum of posttranscriptional behavior for mRNAs from different genes, and of course that, together with transcription and other things, is what gives us the regulation that we have. 


\section{$\$_{\text {CSH\& }}^{\infty}$ Cold Spring Harbor Symposia SYMPOSIA on Quantitative Biology}

\section{A Conversation with David Bartel}

Cold Spring Harb Symp Quant Biol published online December 20, 2019

Access the most recent version at doi:10.1101/sqb.2019.84.039313

$\mathbf{P}<\mathbf{P} \quad$ Published online December 20, 2019 in advance of the print journal.

Creative This article is distributed under the terms of the

Commons http://creativecommons.org/licenses/by/4.0/, which permits unrestricted

License reuse and redistribution provided that the original author and source are credited.

Email Alerting Receive free email alerts when new articles cite this article - sign up in Service the box at the top right corner of the article or click here.

Advance online articles have been peer reviewed and accepted for publication but have not yet appeared in the paper journal (edited, typeset versions may be posted when available prior to final publication). Advance online articles are citable and establish publication priority; they are indexed by PubMed from initial publication. Citations to Advance online articles must include the digital object identifier (DOIs) and date of initial publication.

To subscribe to Cold Spring Harbor Symposia on Quantitative Biology go to: http://symposium.cshlp.org/subscriptions 